\title{
Lactancia: derecho garantizado en el sistema jurídico ecuatoriano. Una mirada desde el enfoque de género y la doctrina de protección integral de la niñez
}

Breastfeeding: guaranteed right in the Ecuadorian law system. An approach from the gender perspective and the integral child protection doctrine Amamentação: direito garantido no sistema jurídico equatoriano. Um olhar desde a perspectiva do gênero e a doutrina da proteção integral das crianças

L'allaitement: droit garantie par le système juridique équatorien. Un regard depuis la perspective de genre et la doctrine de protection intégrale de l'enfance

\author{
Ruth Elizabeth García Alarcón \\ Candidata a doctorado en el Programa de Ciencias Jurídicas y Sociales \\ Universidad Rey Juan Carlos URJC, Madrid - España \\ Correo electrónico: regarcia@puce.edu.ec
}

Cómo citar este artículo:

García, R. E. (2019). Lactancia: derecho garantizado en el sistema jurídico ecuatoriano. Una mirada desde el enfoque de género y la doctrina de protección integral de la niñez. Revista de la Facultad de Derecho y Ciencias Políticas, 49 (131), pp. 327-360. doi: http://dx.doi.org/10.18566/rfdcp.v49n131.a05 Recibido: 13 de febrero de 2019.

Aprobado: 16 de julio de 2019 


\section{Resumen}

La lactancia se ha reconocido, en Ecuador, como un derecho en consonancia con el marco internacional de derechos humanos. A pesar de los esfuerzos para promoverla, persisten situaciones de discriminación en contra de sus titulares. El derecho merece protección específica en virtud de sus características, pero a pretexto de esto no puede exigírsele exclusivamente a la madre lactante esa responsabilidad; ella requiere estar empoderada e informada para decidir. De igual modo, el Estado, como garante de derechos, y la sociedad en general, debe contribuir al pleno goce de la lactancia. Es indispensable combinar el enfoque de derechos humanos, la categoría género y los principios de la doctrina de protección integral de la niñez al analizar el derecho a la lactancia, a fin de garantizar tanto el goce efectivo como el respeto a la autonomía de quienes desean y deciden amamantar. No hay una contradicción entre el ejercicio del derecho y la responsabilidad de su protección efectiva.

\section{Palabras clave}

Derecho a lactancia, género, doctrina protección integral de la niñez, derechos humanos, derechos de mujeres.

\section{Abstract}

Breastfeeding has been recognized as a right in Ecuador in accordance with the international human rights framework. Despite the efforts to promote it, discriminatory situations persist against those entitled to it. The right deserves specific protection on account of its characteristics, but on the pretext of this, the responsibility of it cannot be exclusively demanded from the breastfeeding mother. She needs to be empowered and informed in order to decide, but also the State, as a rights guarantor, and the society in general, must contribute to the full realization of the right to breastfeed. It is essential to combine the human rights approach, the gender category, and the integral child protection doctrine's principles when analyzing the right to breastfeed. All of it in order to guarantee both the effective enjoyment as well as the respect for the autonomy of those who wish and decide to breastfeed. There is no contradiction between the exercise of the right and the responsibility for its effective protection.

\section{Key Words}

Right to breastfeed; gender; integral child protection doctrine; human rights; women rights. 


\section{Resumo}

A amamentação foi reconhecida como direito em Equador segundo o marco internacional dos direitos humanos. Apesar dos esforços para promover a amamentação, continuam situações de discriminação contra seus titulares. O direito merece proteção especifica devido a suas características; contudo essa responsabilidade não se pode exigir exclusivamente à mãe lactante, ela precisa ser empoderada e informada para escolher. Além disso, o Estado como protetor dos direitos e a sociedade em geral têm que favorecer o pleno gozo da amamentação. É preciso articular a perspectiva dos direitos humanos, a categoria do gênero e os princípios da doutrina de proteção integral das crianças quando se analisar o direito de amamentação, com o intuito de garantir tanto o gozo efetivo quanto o respeito à autonomia de quem tem vontade e escolhe amamentar. Não há uma contradição entre o exercício do direito e a responsabilidade de sua proteção efetiva.

\section{Palabras chaves:}

Direito à amamentação, gênero, doutrina da proteção integral das crianças, direitos humanos, direitos das mulheres.

\section{Résumé}

Lallaitement a été reconnu comme un droit en équateur en consonnance avec le cadre international des droits de l'Homme. Malgré les efforts pour le promouvoir, les situations de discriminations persistent contre ses titulaires. Ce droit mérite une protection particulière concernant ses caractéristiques, cependant on ne peut exiger exclusivement à la mère allaitante cette responsabilité. Celle-ci doit être habilitée et informée pour décider mais l'Etat, comme garant des droits, et la société en général doivent contribuer à la jouissance de ce droit à l'allaitement. Il est indispensable de combiner l'approche des droits de l'Homme, la catégorie du genre et les principes de la doctrine de protection intégrale de l'enfance lorsqu'on analyse le droit à l'allaitement afin de garantir tant la jouissance effective comme le respect de l'autonomie de celles qui veulent et décident d'allaiter. Il n’y a pas de contradiction entre l'exercice de ce droit et la responsabilité de sa protection effective.

\section{Mots clés:}

Droit à l'allaitement, genre, doctrine de protection intégrale de l’enfance, droits de l'Homme, droits des femmes. 


\section{Introducción}

Durante el período de lactancia, la madre con su hijo o hija constituyen una unidad biológica y social inseparable por nutrición y vínculo afectivo, pero diferenciada en cada caso. La lactancia como tema de estudio ha sido el foco de diversas disciplinas, tanto por su relevancia en la salud materno infantil, cuanto por el interés como proceso social a favor de su naturalización como práctica cultural ${ }^{1}$ que confronta la dicotomía entre lo privado y lo público. En el ámbito jurídico, también ha sido objeto de estudio; reconociéndose el derecho a la lactancia, estableciéndose garantías para su protección y su ejercicio; por ser la leche humana es insustituible para la salud y para el desarrollo psicológico de niños y niñas, y la salud de las madres lactantes.

El centro del análisis legal respecto de la lactancia se ha limitado al ámbito familiar y laboral ${ }^{2}$; dejando vacíos en la reflexión en el ordenamiento jurídico ecuatoriano. Un análisis adecuado debe incluir los principios de la doctrina de protección integral y el género como categoría de análisis, identificando sus elementos comunes y su complemento mutuo para fortalecer su garantía. Sin embargo se parte de un enfoque en el que no se pone en disyuntiva si se privilegian los derechos de las mujeres sobre los de la niñez ${ }^{3}$.

En primer lugar, se conceptualiza y caracteriza el derecho a la lactancia para identificar la titularidad. En segundo lugar, se revisan, desde el enfoque de derechos humanos, los principios de igualdad y no discriminación, el interés superior del niño, la corresponsabilidad entre Estado, sociedad y familia, y la prioridad absoluta de los derechos de la niñez, contrastados con la teoría de género, especialmente con el empoderamiento de las mujeres y su autonomía para comprender las tensiones en la protección del ejercicio del derecho y la erradicación de discriminación, por visiones adultocéntricas y sexistas.

Finalmente, las conclusiones señalan la importancia de la difusión de la lactancia como un derecho con varios titulares y responsables de su protección prioritaria, y la necesidad de fortalecer la capacidad de las mujeres lactantes para tomar decisiones y demandar frente al Estado su exigibilidad, reconociendo las causas de las situaciones de vulnerabilidad que enfrentan.

Sobre este enfoque ver Massó Guijarro (2013).

2 Ver Agra Viforcos (2006), Andrés, L. (2015) y Marín Alonso (2019) y la crítica que plantea María Amparo Ballester Pastor (2019) sobre la reforma legal en España.

3 No se alinea con el criterio de quienes cuestionan la práctica de la lactancia como una forma de acentuar el patriarcado en perjuicio de la autonomía de la mujer. Ver Butler, J. (2006). 


\section{Derecho a la lactancia}

\subsection{Concepto}

Amamantar es un acto natural y a la vez un comportamiento aprendido, respecto del cual cabe distinguir el alcance de algunos términos. La lactancia materna bien podría denominarse lactancia humana, pues la expresión materna es extensible a toda especie mamífera. La Organización Mundial de la Salud - OMS (2017) define lactancia como:

[L]a ingesta de leche materna lo que excluye el consumo de cualquier otro alimento que no sea el que se deriva del pecho materno, [...] es un acto fisiológico, instintivo, herencia biológica adaptativa de los mamíferos y específica de cada especie.

Por lo tanto, en el contexto de derechos humanos, se circunscribe a la lactancia humana, provista por una mujer biológica. No obstante, de entenderse a la lactancia materna de manera general como "[la] alimentación del recién nacido y lactante, a través del seno materno $[, \ldots]$ existen diferencias en cuanto a su práctica. Estas tienen repercusión en la salud del niño" (Universidad Autónoma de México: 2002, p.1). Entre las diferentes prácticas se encuentra la lactancia exclusiva ${ }^{4}$, la mixta ${ }^{5}$, lactancia con alimentos complementarios ${ }^{6}$, la diferida ${ }^{7}$ y en tándem ${ }^{8}$; las cuales tienen diversos niveles de participación e interacción entre la madre y el lactante de cualquier edad. En cualquier caso, será lactancia si se amamanta, y así debe entenderse a propósito del ejercicio del derech $0^{9}$; incluso si se alimenta con leche humana donada ${ }^{10}$.

4 Sólo leche humana sin ningún otro alimento ni fórmula láctea, de manera continua y en promedio, durante los 6 primeros meses de vida, aunque en los primeros días posteriores al parto, es de color amarillento y se conoce como calostro. Paulatinamente se produce leche madura, de color blanco.

5 Si en una o varias tomas se combina con fórmula u otro sustituto, sea recomendación médica o por criterios relacionados con insuficiencia de producción de leche humana.

6 Etapa de introducción de sólidos, hasta el destete. Se recomienda lactancia exclusiva durante los seis primeros meses y, a partir de entonces, su refuerzo con alimentos complementarios, al menos hasta los dos años (Organización Mundial de la Salud, 2017).

7 Extraída la leche, la madre u otra persona la ofrece al niño, no hay succión directa del seno.

8 Lactan hermanos de distintas edades o el mayor durante el nuevo embarazo.

9 Referencias a "niño lactante" en relación a su edad, aunque no lacte (OMS / UNICEF, 2012).

10 Situación en la que idealmente debería intervenir un banco de leche, tanto para evitar riesgos como para eliminar el peligro de que la leche sea indebidamente comercializada. 
La OMS (2013), UNICEF (2015) e IBFAN ${ }^{11}$ afirman que la lactancia reduce la mortalidad infantil y tiene beneficios hasta la edad adulta, así como para la madre que amamanta (IBFAN: 2006) ${ }^{12}$, con impacto positivo directo en la sociedad (WABA: 2016). Es decir, la leche humana es irremplazable.

A pesar de que lactar y amamantar son actos biológicos y naturales, su práctica ha disminuido de manera generalizada; poniéndose en riesgo la vida de muchos niños (UNICEF: 2018 y El Mundo:2016). De allí la necesidad de reconocerlo como un derecho humano; respecto del cual, el actual debate se centra en su exigibilidad; si amamantar perjudica el ejercicio de algunos derechos de las mujeres, quienes tienen derecho a decidir sobre practicarla y cómo hacerlo; siendo por tanto indispensable profundizar en este análisis desde el ámbito jurídico.

Dentro de la teoría de los derechos humanos, el derecho a la lactancia podría ser categorizado de distintas maneras: como derecho civil, a propósito de un ejercicio de libertades y decisiones sobre la vida privada, personal y familiar. Por vincularse la lactancia con la salud y los derechos a la salud sexual y reproductiva, por seguridad alimentaria o por su impacto para reducir la desnutrición y erradicar la pobreza ${ }^{13}$, podría categorizarse como un derecho de los económicos ${ }^{14}$, sociales y culturales. A propósito de que la lactancia tiene un

11 Red Mundial de Grupos Pro Alimentación Infantil -International Baby Food Action Network: http:// www.ibfan-alc.org/ibfan.htm

12 Ver más en IBFAN (2006) sobre los peligros que presenta el uso innecesario o inadecuado de la leche artificial para lactantes y niños pequeños: mayor riesgo de asma, de alergia, de enfermedad aguda de las vías aéreas, de diabetes, de enfermedad cardiovascular, entre otras; así como para las madres: mayor riesgo de cáncer de mama, de sobrepeso, de cáncer de ovario y endometrio, de osteoporosis, entre otras.

13 "La lactancia materna es una forma natural y de bajo costo de alimentar a los bebés y niños. Es asequible para todo el mundo y los presupuestos de los hogares no se cargan en comparación con la alimentación artificial. La lactancia materna contribuye a la reducción de la pobreza. Previene el hambre, la desnutrición y la obesidad. La lactancia materna también significa la seguridad alimentaria para los niños." WABA, http://worldbreastfeedingweek.org/2016/. Recuperado 15 agosto 2018. También puede resultar interesante revisar esta nota de prensa: Cuál es el precio de un litro de leche materna y por qué Noruega lo cuenta en su PIB https://www.bbc.com/mundo/noticias-48638778.

14 Los estudios sobre costos de la alimentación artificial no solo deben considerar el gasto en comprar fórmulas sino también el gasto en salud pública por complicaciones derivadas en la madre y el hijo. La OMS plantea que: "en las comunidades de bajos ingresos, el costo de la leche de vaca o leche en polvo, más los biberones, chupones, y el combustible para hervir el agua, puede consumir el $25 \%$ al $50 \%$ del ingreso familiar". Sobre el valor económico de la lactancia materna es útil la herramienta elaborada por Alive \& Thrive, con datos de Argentina, Bolivia, Brasil, Guatemala, Honduras, México: https://www.aliveandthrive.org/cost-of-not-breastfeeding/. https://www.who. int/nutrition/publications/infantfeeding/bfhi_trainingcourse_s2_transparencies_es.pdf?ua $=1 . \quad$ Las ventas de sucedáneos de leche materna incrementan anualmente como lo denuncia la prensa: https://www.elespectador.com/noticias/salud/lactancia-un-negocio-que-le-quieren-robar-lasmadres-articulo-863567. 
impacto tan importante en la protección ambiental ${ }^{15}$, incluso, a criterio de la autora, constituye un derecho colectivo o difuso. En todo caso, no es necesario excluir el derecho a la lactancia de una categoría de derechos humanos para encasillarlo en otra, igualmente se aprecia su verdadera importancia e impacto social.

Tanto más que, al igual que el derecho a parir ${ }^{16}$, constituye un proceso natural; la lactancia, conocida como parte de la exterogestación (Massó Guijarro: 2013, p.522) ${ }^{17}$, no requeriría ser declarada como un derecho. Sin embargo, en su práctica, las mujeres lactantes se enfrentan a distintos tipos de relaciones abusivas de poder, por lo que su promoción y difusión deviene fundamental.

En 1990 la OMS y UNICEF declaran e instauran oficialmente la Semana Mundial de la Lactancia Materna -SMLM, para visibilizar que esta práctica debe protegerse, fomentarse y apoyarse. La Alianza Mundial Pro Lactancia Materna $\left(\mathrm{WABA}^{18}\right)^{19}$ la planifica de manera coordinada con otras entidades, así es actualmente el movimiento social más extendido en defensa de un acto natural, el amamantamiento. En el ámbito jurídico Ossorio (2017) define lactancia como:

El lapso durante el cual los recién nacidos se alimentan con leche materna, o algún substitutivo, determina, para las madres trabajadoras, una franquicia horaria para cumplir con esa vital función maternal. Esa rebaja de la jornada se efectúa sin afectar el salario, y suele durar un año o dos, según las legislaciones.

15 "La lactancia materna es una fuente de recursos no contaminante y sostenible, implica menos energía cuando se compara con las industrias de producción de fórmula. También reduce la necesidad de combustibles de agua, leña y fósiles en el hogar" (WABA: 2016).

16 El derecho al parto respetado exige erradicar la violencia obstétrica y garantizar el adecuado inicio de la lactancia. El parto es un acto natural que no requiere ser reconocido como derecho, aunque sí es un derecho que se desarrolle en condiciones sanitarias óptimas y asequibles, con calidad y calidez, como lo contempla la Ley Orgánica para Prevenir y Erradicar la Violencia contra las Mujeres en Ecuador, que entró en vigencia el 5 de febrero de 2018.

17 Es clave la definición de la autora: "La gestación, el parto y la exterogestación, a través de la lactancia materna, constituyen aspectos sexuales para la persona madre; es decir, forman parte de su sexualidad. (...) La exterogestación es una continuación necesaria de la gestación, ya que el ser humano nace prematuro, constituyendo la especie más altricial (lo que se relaciona en proporción directa con la evolución de su neocórtex). Esta exterogestación sucede de forma primordial a través de la lactancia materna".

18 World Alliance for Breastfeeding Action -WABA

19 Cada año se define un lema, a propósito de necesidades puntuales identificadas; desde el 2015 los lemas de la SMLM se vinculan con los Objetivos de Desarrollo Sostenible-ODS. 
Se puede afirmar que el derecho a la lactancia es el derecho tanto de la madre a amamantar a su hijo o hija desde el nacimiento hasta su destete $\mathrm{y}$, cuanto, el derecho de ese niño a mamar, para recibir la leche humana que favorece su nutrición y apego, construyendo un vínculo afectivo durante la crianza y logrando un desarrollo integral que impacta positivamente en el círculo familiar, comunitario y social. Por lo que en las legislaciones de América Latina ya han empezado a generarse cambios en la materia ${ }^{20}$.

\subsection{Normativa relacionada con lactancia}

La construcción del sistema de protección de derechos es el resultado de una constante lucha y búsqueda de consensos desde diversos grupos sociales que han exigido que no solo se les reconozcan los derechos que son comunes para todos los seres humanos, sino que también se visibilicen sus particularidades, debiendo los Estados asumir su responsabilidad como garantes de sus derechos específicos; como en el caso de los derechos de las mujeres y la niñez.

El sistema jurídico ecuatoriano, dentro de los estándares y principios de derechos humanos, reconoce y garantiza los derechos específicos a los niños y niñas lactantes, así como a las mujeres en situación de maternidad y en periodo de lactancia. La Constitución de la República del Ecuador (en adelante Constitución ecuatoriana o CRE) garantiza tanto los derechos reconocidos en esta norma, como aquellos reconocidos en los instrumentos internacionales. Siendo en consecuencia indispensable para el análisis del derecho a la lactancia considerar la Declaración Universal de los Derechos Humanos, el Pacto Internacional de Derechos Económicos, Sociales y Culturales (PIDESC), la Convención para la Eliminación de Todas las Formas de Discriminación contra la Mujer (CEDAW) y la Convención de los Derechos del Niño )CDN); así

20 Colombia obliga a ciertas empresas a organizar espacios conocidos como lactarios (Ley 1823/17). Argentina reconoce a toda trabajadora madre de lactante dos descansos de media hora para amamantar a su hijo en el transcurso de la jornada de trabajo, y por un período no superior a un año posterior a la fecha del nacimiento, salvo que, por razones médicas sea necesario que la madre amamante a su hijo por un lapso más prolongado (Ley 20744, artículo 159). Costa Rica, reconoce una hora de lactancia que puede usar al inicio o al final de la jornada, de común acuerdo con su empleador, también fija la modalidad de pausas (art. 97). En Guatemala, el período de lactancia se empieza a contar desde el primer día en que regresa la mujer a su puesto de trabajo y se extiende a diez meses, se goza de una hora diaria, que puede ser dividida en dos medias horas. En México se reconoce en el periodo de lactancia el derecho a dos reposos extraordinarios de media hora durante una jornada de trabajo para amamantar durante los primeros seis meses de vuelta a las labores, y se garantiza el contar con un lugar adecuado e higiénico (Ley Federal del Trabajo, art. 170). 
como el Código Internacional de Comercialización de Sucedáneos de Leche Materna $^{21}$, la Declaración de Innocenti sobre protección, fomento y apoyo a la lactancia natural (1990).

De acuerdo con el Artículo 35 de la Constitución ecuatoriana, son grupos de atención prioritaria quienes requieren ser atendidos de manera preferencial y especializada para la protección efectiva de sus derechos, por su situación de vulnerabilidad y riesgo ${ }^{22}$; entre los que se encuentran las mujeres embarazadas y a los niños y niñas; así como las mujeres en el período de lactancia (Art. 43). Sobre este grupo de atención prioritaria el Estado garantiza la gratuidad de los servicios de salud materna, la protección prioritaria y el cuidado de su salud integral y de su vida, además de disponer de las facilidades necesarias para su recuperación después del embarazo y durante el período de lactancia (CRE: 2008) ${ }^{23}$.

Sobre la niñez, el Artículo 45 de la Constitución ecuatoriana prevé que los niños "gozarán de los derechos comunes del ser humano, además de los específicos de su edad” y enfatiza en que "el Estado reconocerá y garantizará la vida, incluido el cuidado y protección desde la concepción”. Esto se vincula con la lactancia, que garantiza su sobrevivencia y desarrollo integral, como lo plantea el Artículo 19 de la Convención Americana de Derechos Humanos y la Convención de Derechos del Niño, antecedente del Código de la Niñez y Adolescencia ecuatoriano, en que se establecen mecanismos de protección de los derechos de los niños y otras disposiciones sobre familia.

El primer artículo del Código Orgánico de la Niñez y Adolescencia (en adelante Código de la Niñez o CONA) plantea, en relación con la protección integral, que "el Estado, la sociedad y la familia deben garantizar[la] a todos los niños, niñas y adolescentes con el fin de lograr su desarrollo integral y el disfrute pleno de sus derechos, en un marco de libertad, dignidad y equidad”.

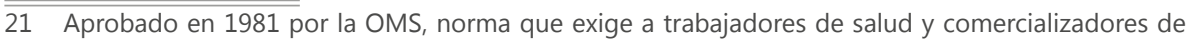
sustitutos de leche materna informar a madres y padres de los peligros que para la salud representa el uso innecesario o inadecuado de la leche artificial o fórmula con información científica y objetiva. El Código de la Salud ecuatoriano incluye restricciones para alimentos en regímenes especiales de lactantes hasta los 12 meses.

22 No se refiere a "grupos vulnerables" puesto que la condición de vulnerabilidad no es esencial sino una situación temporal que no depende de la persona.

23 El artículo 43 de la Constitución ecuatoriana expresamente prevé que: "El Estado garantizará a las mujeres embarazadas y en periodo de lactancia los derechos a: 1. No ser discriminadas por su embarazo en los ámbitos educativo, social y laboral. 2. La gratuidad en los servicios de salud materna. 3. La protección prioritaria y cuidado de su salud integral y de su vida durante el embarazo, parto y posparto. 4. Disponer de las facilidades necesarias para su recuperación después del embarazo y durante el periodo de lactancia". 
El Artículo 15 reitera la titularidad de derechos de niños y niñas y, que además de todos aquellos en favor de todas las personas, gozan de los específicos de su edad, entre los cuales debe considerarse el derecho a la lactancia.

En el mencionado código se incorpora el principio del interés superior de la niñez como principio sustancial de la doctrina de protección integral y también se describe un sistema de protección de derechos, entre los cuales se debe considerar lo relacionado con el derecho a la vida, en donde se enfatiza que ésta se debe asegurar por todos los medios, lo que, de acuerdo con lo planteado sobre salud y desarrollo, incluye la lactancia como mecanismo idóneo; sobre lo que establece:

Art. 24.- Derecho a la lactancia materna.- Los niños y niñas tienen derecho a la lactancia materna para asegurarle el vínculo afectivo con su madre, adecuada nutrición, crecimiento y desarrollo.

Es obligación de los establecimientos de salud públicos y privados desarrollar programas de estimulación de la lactancia materna (CONA: 2003).

Así, en el sistema jurídico ecuatoriano la lactancia es uno de los derechos específicos de la niñez, garantía de una nutrición adecuada. Así también, al establecerlo como "vínculo afectivo" se reconoce que se trata de una relación inherente con la madre, quien es, por lo tanto, otra titular del mismo derecho a la lactancia y se enfatiza también la importancia de la lactancia para la salud en todas sus dimensiones, especialmente la psicológica y física. Por lo que la obligación de promoverla es fundamental; mientras la madre se beneficia del estímulo para lactar que le permite superar dificultades; son también las y los niños quienes se benefician de que su madre pueda darles de amamantar al contar ésta con la información, apoyo y promoción necesaria, de manera prioritaria y especializada como manda la Constitución.

De igual forma, la Ley de Fomento, Apoyo y Protección a la Lactancia Materna define la lactancia materna como "un derecho natural del niño y constituye el medio más idóneo para asegurarle una adecuada nutrición y favorecer su normal crecimiento y desarrollo" (Ley N. ${ }^{\circ} 101$ : 1995); un derecho humano, irrenunciable, intransferible lo cual se evidencia desde el fin mismo de la ley en análisis:

Art. 3. (...) propende a garantizar una nutrición segura y suficiente a los niños recién nacidos que no tengan necesidades especiales de alimentación 
dentro del período de lactancia, mediante el fomento y protección de la lactancia materna y la regulación y control de la comercialización de alimentos infantiles, incluyendo los llamados sucedáneos de la leche materna (Ley N. ${ }^{\circ} 101:$ 1995).

No solo se establece a la lactancia como derecho, se la fomenta, siendo fundamentales los esfuerzos de la autoridad sanitaria para evitar que sea desestimulada mediante formas de comercialización de alimentos sustitutos al margen del interés superior de la niñez ${ }^{24}$.

Con base en la información científica de los organismos especializados, el más alto nivel de salud para niños y niñas, a propósito de la nutrición y el apego, solo se garantiza con lactancia materna; estableciéndose en el Artículo 5 de la Convención sobre los Derechos del Niño que "los Estados partes respetarán las responsabilidades, los derechos y los deberes de los padres” (CDN: 1989) y recalca sus obligaciones en la crianza y desarrollo que, sin duda, de manera implícita, también se refiere a la lactancia materna, como ya se ha explicado:

\section{Art. 18}

1. Los Estados Partes pondrán el máximo empeño en garantizar el reconocimiento del principio de que ambos padres tienen obligaciones comunes en lo que respecta a la crianza y el desarrollo del niño. Incumbirá a los padres o, en su caso, a los representantes legales, la responsabilidad primordial de la crianza y el desarrollo del niño (CDN: 1989).

Esta norma bien podría usarse como argumento para que la madre, titular del derecho a la lactancia, a la vez sea obligada a lactar al hijo. Esta delicada tensión entre el ejercicio del derecho y la responsabilidad de la madre merece un análisis cuidadoso. Es clave considerar que antes de exigirle que lacte a su hijo, se requiere que ella tome una decisión libre, que depende de que haya

24 La Encuesta Nacional de Salud y Nutrición ENSANUT Ecuador 2012 señala que en el grupo de madres que recibieron recomendaciones de fórmulas lácteas, el 75\% tienen hijos menores de 6 meses, a un $15,8 \%$, les recomendaron el uso de varios productos lácteos y al porcentaje restante, $9,2 \%$, otro tipo de fórmula. Por otro lado, en coincidencia con la información que presenta la Encuesta de Liga de La Leche y Voices en Argentina (2018), en México ubican al trabajo materno con el $42 \%$ de incidencia sobre las causas determinantes de abandono de la lactancia exclusiva. Arias de la Torre, Guadalupe y Mejía también concluyen que, entre las principales causas para el abandono de la lactancia materna exclusiva, está el trabajo fuera de casa de la madre. Las otras causas son la producción insuficiente de leche y el rechazo del bebé, ambas pueden estar relacionadas con la discontinuidad en la lactancia a libre demanda o falta de oportunidad de extracción de leche durante la jornada de trabajo, o el método de alimentación aplicado por el cuidador para alimentar al hijo, aún si fuera con la misma leche materna. 
recibido previamente la información adecuada y suficiente además de ser indispensable que se le brinde apoyo especializado, físico y psicológico. Aun entonces, si su decisión es no hacerlo, siempre debería ser respetada, lo que representaría la protección de sus derechos sin discriminación (CEDAW).

La norma constitucional ecuatoriana desarrolla este principio en el Artículo 66, numeral 10, por medio del cual se les garantiza a las personas sus derechos reproductivos, lo que incluye "el derecho a tomar decisiones libres, responsables e informadas sobre su salud y vida reproductiva y a decidir cuándo y cuántas hijas e hijos tener" (CRE:2008). Por otro lado, la lactancia no puede ser vista como una responsabilidad individual, sino que requiere la participación de otros actores, por ejemplo, el padre del hijo o su pareja, la familia en general, el personal de salud, quien sea su empleador (si es el caso), entre otros, conforme lo establece la Constitución ecuatoriana:

Art. 44.- El Estado, la sociedad y la familia promoverán de forma prioritaria el desarrollo integral de las niñas, niños y adolescentes, y asegurarán el ejercicio pleno de sus derechos; se atenderá al principio de su interés superior y sus derechos prevalecerán sobre los de las demás personas. (...) (CRE:2008).

El desarrollo integral de la niñez es el objetivo de la protección de sus derechos y la obligación de garantizarlos es compartida, como plantea el Código de la Niñez, cuando expresamente describe el principio de corresponsabilidad para la garantía, protección y exigibilidad de derechos de la niñez:

Artículo 8.- Corresponsabilidad del Estado, la sociedad y la familia.- Es deber del Estado, la sociedad y la familia, dentro de sus respectivos ámbitos, adoptar las medidas políticas, administrativas, económicas, legislativas, sociales y jurídicas que sean necesarias para la plena vigencia, ejercicio efectivo, garantía, protección y exigibilidad de la totalidad de los derechos de niños, niñas y adolescentes. (...) (CONA:2003).

La familia no tiene categoría de titular de derechos, los titulares son cada uno de sus miembros, pero el Código de la Niñez reconoce el rol que esta cumple como espacio de desarrollo integral:

Art. 9.- Función básica de la familia. La ley reconoce y protege a la familia como el espacio natural y fundamental para el desarrollo integral del niño, niña y adolescente. 
Corresponde prioritariamente al padre y a la madre, la responsabilidad compartida del respeto, protección y cuidado de los hijos y la promoción, respeto y exigibilidad de sus derechos (CONA: 2003).

Se señala así la responsabilidad prioritaria del padre y la madre en todas las fases de garantía de derechos de sus hijos, inclusive en la exigibilidad, que se aplicaría también en el derecho a la lactancia. Para el efecto, a fin de promover el amamantamiento sin restricciones, por mandato del Artículo 10 del Código de la Niñez, es el Estado el que tiene el deber prioritario de definir y ejecutar políticas, planes y programas que apoyen a la familia para cumplir con sus obligaciones, por lo tanto, la responsabilidad de los progenitores no es aislada, requiere articulación con la efectiva decisión y acción estatales y la participación social.

Pero como ya se ha dicho; la lactancia no representa solo un derecho del niño, sino también de su madre lactante, reconociéndose así en el Artículo 25 de la Declaración Universal de los Derechos Humanos (DUDH) que establece que: "La maternidad y la infancia tienen derecho a cuidados y asistencia especiales (...)” (DUDH: 1948). Aunque el texto no visibiliza a la mujer como protagonista de la maternidad, sienta precedente para el desarrollo de normativa nacional e internacional que le brinda protección efectiva, durante esa situación particular.

Con perspectiva de género y para erradicar discriminación la CEDAW asume con firmeza y de manera directa los derechos de las mujeres en situación de maternidad, incluyendo la lactancia. Su Artículo 4 enfatiza que la obligación de los Estados por adoptar medidas especiales "encaminadas a proteger la maternidad no se considerará discriminatoria” y luego, de manera específica y detallada, prevé que se le brinde a la mujer protección en sus derechos laborales y la provisión de servicios sociales para el cuidado de la niñez (CEDAW:1979).

Sobre maternidad y trabajo, en protección de los derechos de las mujeres, el Artículo 23 de la Declaración Universal de los Derechos Humanos reconoce que: "Toda persona tiene derecho al trabajo, a la libre elección de su trabajo, a condiciones equitativas y satisfactorias de trabajo [...] sin discriminación alguna, a igual salario por trabajo igual” (DUDH: 1948). El Pacto Internacional de Derechos Económicos Sociales y Culturales(PIDESC), plantea que el derecho al trabajo debe ejercerse en condiciones justas y satisfactorias, incluyendo el reconocimiento de la licencia parental remunerada y la protección de la niñez, es decir, incluye la lactancia. Y, en este mismo sentido, la Constitución ecuatoriana establece: 
Art. 331.- El Estado garantizará a las mujeres igualdad en el acceso al empleo, a la formación y promoción laboral y profesional, a la remuneración equitativa, y a la iniciativa de trabajo autónomo. Se adoptarán todas las medidas necesarias para eliminar las desigualdades. (...) (CRE:2008).

No obstante de este reconocimiento de derechos, la maternidad y la lactancia han sido las causas de fondo para que muchas mujeres pierdan oportunidades de trabajo, siendo vulnerados sus derechos laborales, al existir pocas medidas efectivas para eliminar desigualdades. La Constitución ecuatoriana expresamente se refiere a la lactancia cuando dispone:

Art. 332.- El Estado garantizará el respeto a los derechos reproductivos de las personas trabajadoras, lo que incluye la eliminación de riesgos laborales que afecten la salud reproductiva, el acceso y estabilidad en el empleo sin limitaciones por embarazo o número de hijas e hijos, derechos de maternidad, lactancia, y el derecho a licencia por paternidad. Se prohíbe el despido de la mujer trabajadora asociado a su condición de gestación y maternidad, así como la discriminación vinculada con los roles reproductivos (CRE:2008).

Estos derechos están también reconocidos en los convenios de la Organización Internacional del Trabajo -OIT, especialmente en el Convenio $\mathrm{N}$. ${ }^{\circ} 183$ del año 2000 sobre maternidad y pausas para el amamantamiento ${ }^{25} \mathrm{y}$ en la Recomendación N. ${ }^{\circ} 191$ sobre protección de maternidad del mismo año.

Particularmente sobre relaciones laborales y lactancia, la normativa secundaria ecuatoriana se encuentra tanto en el Código de Trabajo como en la Ley Orgánica del Servicio Público (en adelante LOSEP) ${ }^{26}$. La más reciente reforma al Código del Trabajo en esta materia fue la denominada Ley para la Justicia Laboral y el Trabajo en el Hogar (LJLTH: Registro Oficial N. ${ }^{\circ} 483$ del 20 de abril de 2015), incorpora el concepto de despido ineficaz estableciendo:

Art. 195.1 Prohibición de despido y declaratoria de ineficaz. Se considerará ineficaz el despido intempestivo de personas trabajadoras en estado de

25 El informe publicado por la OIT (2010), La maternidad en el trabajo: examen de la legislación nacional muestra que, en al menos 92 países, la legislación ya establece pausas para el amamantamiento, además de las interrupciones regulares, para las madres en período de lactancia.

26 La única diferencia de derechos de lactancia entre trabajadoras en sector público y en sector privado en Ecuador es que actualmente la obligatoriedad de establecer lactarios no rige en el sector público, ni las respectivas pausas para extracción. Norma para uso de salas de apoyo a lactancia materna, sector privado, 2019. Las dos horas de jornada reducida se aplican en ambos casos, así como la posibilidad de extender hasta un año la licencia no remunerada. 
embarazo o asociado a su condición de gestación o maternidad, en razón del principio de inamovilidad que les ampara (LJLTH:2015).

Verificándose que el despido ineficaz incluye la protección de los derechos laborales de la mujer lactante; siendo una de las principales características de la figura del despido ineficaz que se declare al despido como nulo y que, por lo tanto, se reintegre nuevamente a la persona trabajadora a sus funciones. Es decir, que se le readmita, y así mismo, se le imponga al empleador una sanción por haber incurrido en una prohibición; impidiendo efectivamente que se termine la relación laboral de la mujer lactante y que durante las doce semanas de permiso de maternidad perciba su remuneración completa. Igualmente, la Ley Orgánica del Servicio Público dispone, en su Artículo 27, prevé que se concederá licencia con remuneración a las servidoras públicas, por el mismo periodo de doce semanas.

Otra de las garantías para el ejercicio de la lactancia de la mujer trabajadora es la reducción de la jornada laboral en dos horas; que se aplica sea que se practique o no la lactancia. Es decir, puede ser solo para el cuidado del niño o niña, conforme claramente lo establece el artículo 33 de la Ley Orgánica del Servicio Público que prevé que "las servidoras públicas tendrán permiso para el cuidado del recién nacido por dos horas diarias, durante doce meses contados a partir de que haya concluido su licencia de maternidad” (LOSEP:2010).

La vigilancia del cumplimiento corresponde a las autoridades laborales; con el apoyo de la Policía Nacional para dar cumplimiento con lo dispuesto dentro de la normativa legal vigente; existiendo además la vía judicial. La autoridad administrativa, un inspector de trabajo, recibe la queja, debe convocar al empleador a una audiencia, para verificar la procedencia del reclamo y en ciertas ocasiones, la comparecencia da lugar a rectificar alguna acción indebida; sin embargo, la relación laboral generalmente queda afectada y no es común la denuncia.

En los registros del Ministerio del Trabajo no existe información desagregada de denuncias específicamente por amenazas o vulneraciones al derecho de lactancia. En los años 2017-2018, el número de denuncias recibidas por asuntos de maternidad, en general, incluye las de lactancia es relativamente bajo, como se aprecia en el cuadro adjunto; pudiendo inferirse un número de causas judiciales aún menor. Esto supone que las mujeres trabajadoras preferirían sobrellevar en lugar de presentar un reclamo para que se cumpla la normativa. 
Tabla 1. Denuncias relativas a asuntos relacionados con la maternidad 2017-2018

\begin{tabular}{|c|c|c|}
\hline CIUDAD & $\mathbf{2 0 1 7}$ & $\mathbf{2 0 1 8}$ \\
\hline Quito & 63 & 57 \\
\hline Cuenca & 0 & 1 \\
\hline Ibarra & 0 & 0 \\
\hline Guayaquil & 7 & 2 \\
\hline Portoviejo & 4 & 4 \\
\hline Loja & 0 & 0 \\
\hline Ambato & 1 & 3 \\
\hline TOTAL & 75 & 67 \\
\hline
\end{tabular}

Esto, sumado a la falta de controles regulares de oficio, implica que las violaciones laborales solo se investigan en aquellos casos concretos en que precede una denuncia de parte de la trabajadora directamente afectada. Por lo que, aun cuando la autoridad administrativa podría actuar de oficio, no lo hace, esto deja a la mujer en una situación de desprotección. A lo cual se agrega que a las madres que han intentado denunciar, reportaron que se les sugirió iniciar acciones judiciales, frente a lo cual decidieron declinar las acciones.

A propósito de derechos laborales y lactancia, es necesario también dejar constancia de la reforma laboral del año 2016 con la denominada Ley Orgánica para la Promoción del Trabajo Juvenil, regulación excepcional de la jornada de trabajo, cesantía y seguro de desempleo, en la que se plantea la licencia opcional y voluntaria, pero sin remuneración, a la que pueden acceder la madre o el padre, durante nueve meses adicionales a la licencia de maternidad, sin perder cómputo de antigüedad. En cuyo caso, puede aprovecharse este tiempo para mantener la lactancia sin dificultades relacionadas con la ausencia de la madre; sin embargo, no existen aún estudios que permitan demostrar el grado de incidencia en la aplicación de esta opción.

Finalmente, la revisión normativa se completa con la que se refiere a la igualdad formal, material y la no discriminación prevista en el Artículo 66.4 de la Constitución que consagra que se les reconoce y garantiza a todas las personas ese derecho. Para cerrar las brechas de desigualdad y exclusión histórica que han vulnerado derechos, en este caso, especialmente a mujeres y niños, la Constitución ecuatoriana prevé la adopción de medidas de acción 
afirmativa que promuevan la igualdad real a favor de titulares de derechos que lo requieren, mientras prohíbe la discriminación por edad, sexo, entre otras categorías. Disposición que se refuerza en el Código de la Niñez que en su artículo 6 prevé:

Todos los niños, niñas y adolescentes son iguales ante la ley y no serán discriminados por causa de su nacimiento, nacionalidad, edad, sexo, etnia, color, origen social, idioma, religión, filiación, opinión política, situación económica, orientación sexual, estado de salud, discapacidad o diversidad cultural o cualquier otra condición propia o de sus progenitores, representantes o familiares.

El Estado adoptará las medidas necesarias para eliminar toda forma de discriminación (CONA:2003).

El ejercicio del derecho a la lactancia ha generado situaciones de discriminación, especialmente desde la visión adultocéntrica y sexista ${ }^{27}$. Por un lado, se desvaloriza su importancia, y por otro, hasta se cuestiona la decisión de practicarla sin restricciones. Por este motivo, es relevante analizar la inclusión y la igualdad de los titulares principales de este derecho, el niño o niña y la madre. Planteado este contexto legal sobre la lactancia como derecho en Ecuador, es importante señalar sus características.

\subsection{Características del derecho a la lactancia}

El derecho a la lactancia tiene características jurídicas especiales, una de ellas, la doble o múltiple titularidad, como se planteará a continuación, distinguiendo entre titulares principales y titulares vinculados. Paralelamente, será importante identificar quienes tienen la responsabilidad de garantizar el derecho, como lo plantea Bidegain Ponte:

[E]l marco de derechos humanos permite delimitar claramente quiénes son titulares de derechos y quiénes titulares de deberes y, de esta forma, se

27 Adultocéntrico se refiere al enfoque que invisibiliza a la niñez y sus derechos, con una visión de superioridad, ver más en: https://unicef.cl/web/wp-content/uploads/2012/12/UNICEF-04SuperandoelAdultocentrismo.pdf

Sexista se refiere a la conducta que desvaloriza a una persona por su sexo al atribuir condiciones estereotipadas, ver más en: https://www.un.org/es/sections/issues-depth/gender-equality/index. html 
establecen contratos sociales claros, mecanismos de exigibilidad de los derechos y medidas tendientes a reducir las desigualdades. El papel activo de los Estados queda claramente definido. Por un lado, los Estados deben proteger, respetar y cumplir los derechos humanos de las mujeres y las niñas (obligaciones positivas), incluso fuera de sus fronteras y, por otro, deben abstenerse de interferir o limitar el disfrute de los derechos (obligaciones negativas). Además, los Estados deben asegurar que agentes no estatales, por ejemplo, el sector empresarial, respeten los derechos humanos y actúen con diligencia debida (Bidegain Ponte:2017, p.21).

Vale la pena detenerse a analizar estas características jurídicas de manera disgregada:

a) Múltiple titularidad: En el sistema jurídico ecuatoriano se reconoce a la mujer en situación de maternidad como una de las titulares del derecho a la lactancia, y de manera concreta, se refiere a ella. Es decir, siempre que esté debidamente informada, antes o desde el mismo momento del parto, la madre debería decidir libremente si quiere o no ejercer el derecho a amamantar al recién nacido y no depender de la opinión de terceros. Debe respetarse su decisión de amamantar, sea expresa o tácita, sin consideración de la edad de la madre $^{28}$. Con anterioridad, el personal sanitario le debe proveer de información adecuada y de apoyo especializado para que ella como titular del derecho, lo ejerza mientras dure esa relación de amamantamiento, hasta el destete ${ }^{29}$.

En el caso de que la mujer no sea la madre biológica del recién nacido, por ejemplo, o en el escenario de una adopción o acogimiento, tras decidir y lograr estimular la producción de leche materna, incluso mediante medicamentos, ella es también, indiscutiblemente, titular del derecho a la lactancia.

$\overline{28}$ El alto índice de madres adolescentes debe ser tomado en cuenta, porque son situaciones de doble vulnerabilidad. Si se trata de víctimas de violencia sexual, también es indispensable garantizar a la madre su derecho a una atención especializada para afrontar la maternidad y la lactancia. Ver más en: https://www.elcomercio.com/actualidad/ecuador-estadisticas-embarazo-adolescente-mama. html Recuperado el 30 de mayo de 2018.

29 Cabe resaltar que la decisión de la madre por amamantar o no y hasta cuándo hacerlo debe ser tomada únicamente en ejercicio de su autonomía, es decir, debe cumplirse la condición de que tenga acceso a información veraz y actualizada, aún si la salud de su hijo puede enfrentar riesgos. Así como no cabe que la mujer sea forzada en contra de su voluntad a lactar, tampoco puede ser obligada a desistir de hacerlo. 
También existen casos de personas transgénero masculino, que han gestado biológicamente a sus hijos y que, por lo tanto, los han lactado ${ }^{30}$; siendo también titulares del derecho como progenitor lactante, aunque su identidad ya no sea femenina ${ }^{31}$,así, podría ser el progenitor lactante alguien con género masculino.

La normativa en Ecuador, de manera explícita, señala el otro titular del derecho a la lactancia: el niño o niña, quien ${ }^{32}$, desde su nacimiento, prematuro o a término por período gestacional, depende totalmente de la decisión, capacidad y las oportunidades reales con las que cuenta su madre para exigir que se respete su derecho. La unidad biológica y social de la madre y su hijo o hija, en el ámbito de la salud, se conoce como diada lactante, que ejerce su derecho desde el parto hasta el destete, que puede ocurrir hasta algunos años después. De acuerdo con la recomendación de la OMS, la lactancia debe practicarse al menos hasta el segundo año de vida, es decir, se recalca en al menos, puesto que la lactancia puede mantenerse por el tiempo que la diada lactante lo prefiera, y nadie más podría impedirlo ni forzar su finalización.

En ocasiones, la madre puede iniciar una segunda gestación y continuar lactando en tándem al hijo o hija mayor, incluso hasta después del siguiente nacimiento, y en esa continuidad, la madre es la misma titular del derecho, pero respecto de dos lactantes de distintas edades, cada uno también mantiene titularidad.

Por supuesto que, según el contexto cultural, e inclusive, sin considerar la decisión de la madre, el niño o niña puede ser alentado a lactar o, al contrario, forzado al destete precoz, lo que genera una vulneración al ejercicio del derecho a la lactancia y a otros derechos como el de la salud, que deben mirarse como interdependientes.

Si bien la madre y el niño o niña pueden considerarse los titulares principales, en el derecho a la lactancia, cabe considerar que habría otros titulares vinculados. Se trata del padre del niño o niña, o la pareja de su madre, si

30 Ver más en: https://www.llli.org/informacion-sobre-la-lactancia-materna-de-la-a-a-la-z/apoyo-para-parentalidadestransgenero-y-no-binarias/ y https://www.llli.org/identidad-de-genero-papa-transgenero/ Recuperado el 30 de enero de 2019.

31 La Ley Orgánica de Gestión de la Identidad y Datos Civiles permite que, por autodeterminación, en la identificación una persona adulta escoja si prefiere que conste su sexo o su género (arts. 78 y 94).

32 De acuerdo con la CDN, la etapa de la niñez incluye la adolescencia; sin embargo, para efectos de la lactancia, serían solo los primeros años de vida. El primer artículo señala: "Para los efectos de la presente Convención, se entiende por niño todo ser humano menor de dieciocho años de edad". 
asume la responsabilidad compartida en el proceso de crianza y alimentación. Los derechos de esta persona deben ser tomados en cuenta, aunque no sea directamente quien lacte, pero participa en la toma de decisiones que pueden favorecer o perjudicar la lactancia e incluso, puede aportar patrimonialmente para que se goce de ella. En España, por ejemplo, la titularidad del permiso de lactancia de la trabajadora puede transferirse al padre (Estatuto de Trabajadores, Art. 37.4.), quien podría apoyar en la lactancia diferida, caso contrario, si la lactancia ya no se practica, sería responsable de la alimentación del hijo.

b) Corresponsabilidad en la protección: Además del Estado como garante del derecho, en la lactancia se identifican otros actores sociales como responsables. Por una parte, la madre que, como se ha dicho, tiene un doble rol; por lo que siempre que sea posible debería estar informada para decidir sobre cómo practicar la lactancia, o incluso contar con la información para poder decidir no hacerlo; orientada adecuadamente, por ejemplo, por personal del sistema sanitario, que tiene responsabilidad de capacitarse para proveer atención especializada. Es cierto que la lactancia puede no ser la mejor opción para todas las madres, aunque lo sea para casi todos los bebés, excepto los que enfrentan circunstancias excepcionales ${ }^{33}$. Por otro lado, el padre, los miembros de la familia y toda persona relacionada con la madre o el hijo, tienen la responsabilidad de proteger el ejercicio del derecho, aún en espacios públicos. Otros actores responsables son las empresas que comercializan productos sucedáneos de leche materna que no deben promocionar sus productos de manera indebida. En el ámbito laboral, son responsables los empleadores y dirigentes sindicales, que deberían incluir, entre sus asuntos prioritarios de negociación, lo relacionado con permisos de lactancia.

c) Ejercicio amplio en duración, continuidad y espacio: Son otras características del derecho a la lactancia, que actúan de manera interconectada en cada sesión de amamantamiento diurna o nocturna, directa o en diferido, su frecuencia es variable según distintos factores, como la edad de cada niño, por lo tanto, su garantía es permanente. El ejercicio de este derecho inicia en el nacimiento o parto, si es un hijo biológico, o inicia cuando sea posible si por alguna dificultad se impidió la lactancia inmediata, o si hay decisión de la madre adoptante. Lamentablemente, algunas prácticas hospitalarias

Madres con VIH o en tratamiento de quimio o radioterapia. Bebés con MSUD (causada por una anomalía genética) o con galactosemia (enfermedad enzimática hereditaria, transmitida como rasgo autosómico recesivo, ocurrencia aproximada de 1 por cada 60000 nacimientos entre personas blancas, mientras que la tasa es diferente para otros grupos. OMS (2009). 
restringen o limitan el ejercicio de este derecho, aunque el recién nacido se encuentre en buenas condiciones de salud ${ }^{34}$, de este modo, vulneran el derecho quienes no estimulan ni apoyan la lactancia.

En el otro extremo está la etapa de destete definitivo del lactante, que debería ser el resultado de un proceso gradual y respetuoso, nunca impuesto por nadie que no sea decisión de la díada lactante, pues antropológicamente se ha determinado que en los humanos la franja de lactancia se sitúa hasta los dos y siete años. Por lo tanto, superando criterios culturales variables, la lactancia debe durar lo que la madre y su hijo decidan que dure ${ }^{35}$.

La continuidad supone constancia y disponibilidad a libre demanda, sin límite de tiempo o espacio. Las complicaciones para lactar en público se deben a las constantes limitaciones de culturas patriarcales. Se ha pretendido que se circunscriba al espacio doméstico, lo que obliga a la madre a mantenerse dentro de su hogar, como espacio privado y asignado para el rol reproductivo. En el Ecuador no ha sido necesario que se reconozca el derecho de lactar en espacios públicos, aun así se han desarrollado campañas a su favor, para que no se pierda la percepción de su naturalidad ${ }^{36}$.

Si la madre trabaja fuera del hogar no hay motivo para suspender el goce de este derecho. La ley favorece la lactancia mediante permisos o jornadas reducidas, y a través de la obligación legal de implementar lactarios, que faciliten la lactancia con sesiones de amamantamiento y extracción, lo que también supone que se garanticen las condiciones mínimas para hacerlo en su lugar de trabajo. Solo cuando el empleador no permite a la trabajadora ejercer su derecho, el Estado interviene para exigir el cumplimiento de las obligaciones patronales.

34 Los horarios y salas cuna para todo recién nacido, por ejemplo, perjudican la lactancia.

35 Ver más en: Entrevista al pediatra Carlos González, experto en lactancia: 'La edad normal del destete debe estar entre los dos años y medio y los siete'. https:/www.elmundo.es/ elmundosalud/2009/08/01/mujer/1249085191.html - Información de la Liga de La Leche Internacional; https://www.Illi.org/informacion-sobre-la-lactancia-materna-de-la-a-a-la-z/ ; y, en Kneidel, Sally, Lactando pasado el primer año (Nursing Beyond One Year), New Beginnings), Vol. 6, No. 4, julio-agosto 1990, págs. 99-103.

36 En políticas públicas, el Plan Nacional se refiere explícitamente https://www.todaunavida.gob.ec/ la-lactancia-materna-es-decisiva-en-la-reduccion-de-enfermedades-y-mortalidad-infantil/ y el Ministerio de Salud Pública ha realizado regularmente campañas como las de apoyo a la Semana Mundial de la Lactancia Materna y el reconocimiento a entidades que establecen lactarios, ver en https://www.salud.gob.ec/semana-mundial-de-lactancia-materna-impulsa-el-apoyo-a-las-madresque-amamantan/. 
Una vez revisadas estas características del derecho a la lactancia, corresponde analizar que en su ejercicio confluyen diversos enfoques que se complementan entre sí y que no deberían entrar en conflicto.

\section{Enfoques y principios doctrinarios aplicables a la lactancia}

\subsection{Principio de igualdad, inclusión y no discriminación}

El enfoque de derechos humanos con el complemento de la perspectiva de género y la doctrina de protección integral de la niñez favorecen el análisis jurídico de los derechos de las mujeres y de la niñez, que, como se ha dicho, son los titulares principales del derecho a la lactancia.

La brecha entre la igualdad formal y real tiene una dimensión especial en el ejercicio del derecho a la lactancia, las condiciones físicas, sociales y económicas en las que se encuentran las madres y sus hijos van a determinar que sea o no ejercido a plenitud el derecho. Reconocer a la lactancia como un derecho humano ha permitido que las mujeres y los niños puedan practicarla bajo un marco de garantías, pero también persisten muchas maneras de provocar discriminación, ya que la sociedad pone obstáculos para su libre goce.

Las situaciones de discriminación directa son cada vez más escasas, mientras que persisten las situaciones que generan discriminación indirecta, que hacen más difícil que el derecho se pueda ejercer, ya que en apariencia el ejercicio del derecho es neutro, pero se aplican requisitos o condiciones que limitan el acceso a las oportunidades, con un resultado que genera un impacto desigual. Salgado (2010, p. 139) sostiene que "la discriminación indirecta fortalece los prejuicios colectivos y por eso se requiere superarlos en el ámbito familiar, educativo, laboral y comunitario”. La dificultad de demostrar la discriminación indirecta la ha señalado la Comisión Interamericana de Derechos Humanos -CIDH (2007):

[E]n el caso de las discriminaciones indirectas, hace falta probar el efecto o resultado desproporcionadamente perjudicial que tiene ese criterio sobre un grupo o colectivo. En este caso, acreditar la existencia de discriminación 
supone aportar datos empíricos que demuestren que el supuesto sesgo "invisible" o "neutral" en la adopción de decisiones tiene un efecto dispar sobre algún grupo o sobre grupos determinados (CIDH:2015, párr. 91).

Por este motivo, se evidencia la discriminación indirecta que vulnera el derecho a la lactancia cuando se presiona a la madre lactante para que ofrezca alimentación artificial, se cuestiona su capacidad para alimentar a su hijo con leche materna o se promueven el uso de sucedáneos alimenticios desgastando su seguridad y se sugiere descontinuar la lactancia para mantener el trabajo. Hay discriminación cada vez que a la mujer que amamanta se le cierran oportunidades de empleo, de ascenso en su trabajo o se debilita su estabilidad laboral, puede ser incluso discriminación institucional, que en relación de dependencia se aplica mediante reglas, políticas, procedimientos o prácticas, de acuerdo con los parámetros de interpretación de derechos humanos (ius cogens) establecidos por los organismos internacionales respecto de la discriminación indirecta.

De esta manera, se distingue la igualdad de jure, legal o formal de la de facto, sustantiva, genuina o igualdad material. La primera es la que reconoce en la norma a toda persona como igual y que tiene los mismos derechos, mientras la segunda es entendida como aquella que se alcanza cuando ha sido posible superar las diferencias y desigualdades reales y para esto es importante la aplicación de medidas de corrección o acciones afirmativas que permitan cerrar las brechas de la desigualdad.

Lydia Andres (2015, p.24) afirma que el Estado ecuatoriano todavía sigue trabajando en el cumplimiento de los instrumentos internacionales sobre derechos de las mujeres, pero sí se debe reconocer el camino transitado. Esto explica que, analizando comparativamente la legislación de varios países latinoamericanos; Pautassi, Faur y Gherardi (2006) escribían:

En el caso de Ecuador, es el país que mayor especificidad otorga a garantizar el trabajo de las mujeres, al punto tal que establece que se reconocerá como labor productiva el trabajo doméstico no remunerado e incorpora acciones afirmativas en el texto constitucional (Pautassi, et al.:2006, p.59).

Ecuador tiene una Constitución progresista en derechos de las mujeres, perspectiva de género $\mathrm{y}$, específicamente, en lo atinente a los derechos relativos a la maternidad y a la paternidad; y, particularmente la lactancia. № obstante, de acuerdo con la Recomendación General 25 del Comité CEDAW 
(2004, parágrafo II) el enfoque jurídico o programático formal no es suficiente para lograr la igualdad de facto:

[S]e requiere que la mujer tenga las mismas oportunidades desde primer momento y disponga del entorno que le permita conseguir la igualdad de resultados. No es suficiente garantizar a la mujer un trato idéntico al del hombre. El logro del objetivo de la igualdad también exige una estrategia eficaz encaminada a corregir la discriminación (CEDAW: 2004, parágrafo 8).

Precisamente, es imposible de exigir en el ejercicio del derecho a la lactancia el trato idéntico, en pie de igualdad, con los hombres. Al contrario, es indispensable valorar las diferencias, en los distintos ámbitos en los que el derecho debe ser garantizado, y la eficacia de las estrategias suponen la participación activa de mujeres empoderadas que, en condición de maternidad y especialmente en período de lactancia, reportan reiteradamente sobre las situaciones de discriminación que han enfrentado. El principio prohíbe la discriminación, no la diferenciación, como lo plantea Cajas:

Se dice que existe una paradoja particularmente en los debates de los movimientos feministas, porque reclaman igualdades entre hombres y mujeres, y reclaman el derecho a la diferencia o diversidad, pero en realidad no existe tal paradoja, ya que lo contrario de la igualdad es la desigualdad, no la diferencia. La doctrina ha identificado el parámetro de 'razonabilidad' para determinar el criterio que nos permita establecer cuando un tratamiento diferenciado es discriminatorio o no (Cajas: 2011, p.171).

Ester Massó reconoce los “numerosos prejuicios de que es objeto la lactancia materna, prejuicios que sustentan falacias presentes en muchas reflexiones críticas sobre la lactancia desarrolladas desde ciertos sectores del feminismo" (Massó:2013, p.171). Ha sido Butler (2006) una de las feministas que ha planteado que las críticas a la lactancia, en su criterio, afectan la autonomía de las mujeres. El contexto desde el cual explica que no se miraba a la lactancia como un derecho, y que para exigir su ejercicio han sido precisamente las mujeres las que han levantado la voz, revestidas de un empoderamiento que solo demuestra que la practican como una reivindicación de su autonomía. Las diversas vertientes del feminismo han promovido la igualdad de género para superar la subordinación y discriminación del sistema patriarcal (Williams, 2009, p. 262 y Facio, 1999) para lo que ha sido necesaria la deconstrucción de las normas jurídicas y sociales androcéntricas, y por eso, la lactancia se ve ahora como una herramienta de empoderamiento de las mujeres. 
El empoderamiento es un proceso individual y colectivo de adquisición de poder en varios sentidos: "[E]s el poder sobre una misma, el poder tomar decisiones sin tutela alguna y es también ser portadora de poder frente a las demás personas” (Bareiro, 2016). Logra ampliar capacidades, nuevas oportunidades, tomar decisiones estratégicas y cambios en la distribución de recursos.

Para Boaventura De Sousa Santos (2003) la igualdad real se logra superando prejuicios y estereotipos sexistas, con tratamiento igual o diferente según sea la situación, lo que es contrario al criterio que las desigualdades naturales son insuperables e incorregibles, dando importancia exagerada a las diferencias biológicas e invisibilizando las grandes similitudes entre hombres y mujeres para asignarles roles y comportamientos diferentes y desiguales que, como señala Facio (1999) indebidamente valoran como superior lo masculino sobre lo femenino. Bidegain Ponte (2017) lo plantea así:

El enfoque de derechos en la formulación e implementación de la política pública evita la priorización de unos derechos de las mujeres por sobre otros ya que los derechos son indivisibles y permite identificar y corregir los sesgos de género de las políticas públicas (Bidegain Ponte: 2017, p.22).

Sin embargo, en el derecho a la lactancia, las diferencias biológicas sí son esenciales y amamantar a un ser humano es efectivamente importante para todos los actores involucrados, y no puede considerarse como una opción de alimentación, sino que debe reconocérselo como un derecho que debe ser garantizado.

\subsection{Conexiones entre los principios de la Doctrina de Protección Integral y la teoría de género}

La doctrina de protección integral (DPI) introdujo una nueva visión de la niñez, y tiene en su esencia la afirmación de que todo niño o niña es sujeto de derechos y no un incapaz objeto de protección como se lo consideraba antes de la vigencia de la Convención de Derechos del Niño. Los niños y niñas son titulares de todos los derechos humanos además de los específicos de su edad, y estos derechos pueden ser ejercidos de manera progresiva, concepto que cambia el paradigma adultocéntrico y replantea su relación con los adultos, inclusive sus progenitores, y con el Estado. 
Con respecto a los derechos específicos, la Corte Interamericana de Derechos Humanos ha expresado que "los niños poseen los derechos que corresponden a todos los seres humanos - menores y adultos - y tienen además derechos especiales derivados de su condición, a los que corresponden deberes específicos de la familia, la sociedad y el Estado” (CorteIDH: Opinión Consultiva OC-17/2002 párr. 54). La necesidad de ofrecerles protección adicional y adoptar medidas o cuidados radica en que niños y niñas se encuentran en una etapa de crecimiento.

Los principios de la DPI son el interés superior del niño, la igualdad y no discriminación, la prioridad absoluta de los derechos de la niñez y la corresponsabilidad entre Estado, sociedad y familia, todos ellos están incorporados en el sistema jurídico ecuatoriano y cobran especial importancia en el derecho a la lactancia.

El interés superior del niño ha sido un principio que ha provocado diversas interpretaciones, por lo que finalmente el Comité de Derechos del Niño planteó la Recomendación General No. 14 que permite distinguir al interés superior como principio, derecho y norma de procedimiento. Nos recuerda Cillero (1999) que:

Como las niñas y los niños son parte de la humanidad y sus derechos no se ejercen separada o contrariamente al de las otras personas, el principio no está formulado en términos absolutos, sino que el interés superior del niño es considerado como una “consideración primordial”. El principio es de prioridad y no de exclusión de otros derechos o intereses.

Esto significa que, a propósito de la lactancia materna, esta puede ejercerse en la medida que no exista conflicto de intereses con los derechos de la madre, como si existe riesgo de la salud materna. Por otro lado, la madre siempre puede tomar la decisión de no lactar, en ejercicio de su autonomía.

La condición de vulnerabilidad que tienen los niños y niñas por su dificultad de afrontar situaciones de riesgo no puede restringir su titularidad de derechos, al contrario, marca la obligación de atenderlos de manera prioritaria y especializada; debiendo superarse la visión paternalista y tutelar respecto a la infancia vista como objeto de protección. Aunque la lactancia se ofrece en edad temprana, al inicio la decisión es de la madre, pero luego sí deben también respetarse las necesidades del niño. Los principios de la DPI deben, por lo tanto, complementarse y no entrar en confrontación con los elementos 
de la teoría de género, especialmente con lo relativo al empoderamiento y autonomía de las mujeres y sus planes vitales.

La autonomía de las mujeres es definida como "la capacidad para tomar decisiones libres e informadas sobre sus vidas, de manera de poder ser y hacer en función de sus propias aspiraciones y deseos, en el contexto histórico que las hace posibles" (CEPAL 2011, p.9). Por lo tanto, si la lactancia es un derecho, se requiere tener conciencia del mismo, del alcance de su protección y de las formas de su ejercicio. La madre principalmente debe recibir la información adecuada y tener acceso a apoyo especializado para tomar decisiones libres y, solo entonces, en ejercicio de su autonomía, cada madre puede optar por practicarla, y tampoco debería sentirse forzada a descontinuarla. El análisis que hace Massó (2013) sobre esta situación que ya cobra apariencia de dilema, le lleva a concluir que:

[L]os relativamente recientes movimientos sociales de apoyo a la lactancia materna, encabezados por grupos de mujeres autodenominadas feministas, ponen de relieve que este fenómeno resulta altamente polifacético en su implementación, interpretación y agencia social por parte de las propias madres lactantes (Massó:2013, p.170).

Como muestra de esta problemática y, a pesar de la prioridad consagrada en la protección de derechos de la niñez, en el campo laboral tampoco hay garantías suficientes para las trabajadoras lactantes. La visión del empleador generalmente tiende a mirar estas condiciones como cargas o costos adicionales y por tanto se buscan caminos para evitarlas; existiendo reducida preocupación social por garantizar estos derechos. Conforme se señaló las autoridades competentes prácticamente no controlan ni establecen medidas de prevención en contra de discriminación. Las mujeres deben elegir entre mantener su puesto de trabajo o continuar con la lactancia, cual si fueran a actividades incompatibles. Massó (2013) recuerda que se recurre con frecuencia a la frase tantas veces proclamada de "sacrifícate por tu bebé"; al respecto la autora comenta que:

No se trata del sacrificio; si lo fuera, se propondría en pie de igualdad o como método incluso superior, por ejemplo, la generalización de la extracción de la leche (o hasta su producción en laboratorios, asunto hoy que todavía se dista mucho de lograr), para alimentar convenientemente a los bebés "en diferido" sin el necesario concurso de los pechos maternos a tiempo real. (Massó:2013, p. 176) 
Entonces, la cultura de crianza experimenta grandes cambios a propósito del trabajo femenino remunerado fuera del hogar, con servicios de cuidado del recién nacido costosos y pocos espacios reservados para extracción de leche materna o amamantamiento. Como consecuencia, la evolución en las prácticas sociales del cuidado también converge sobre otras posibles opciones de alimentación, con lo cual se le resta importancia al amamantamiento. Luego, corresponde hacer eco de las palabras de Massó (2013) que sostiene que no solo es crucial defender la lactancia desde la perspectiva unilateral de los derechos de los bebés a ser amamantados, sino también como "reclamo feminista, entre otros; la lactancia materna como buena para las mujeres, en particular, y las culturas, en general; y, por tanto, la lactancia materna como objetivo feminista” (Massó: 2013, p.175).

Evidenciándose que falta mucho para materializar políticas públicas se debe dar prioridad a las mujeres y "la infancia estableciendo mecanismos para promover preferentemente el desarrollo de las niñas y los niños y amortiguar los efectos de las restricciones económicas o sociales" (Cillero:1999).

\section{Conclusiones}

Durante la lactancia, la mujer y su hijo o hija lactante deben considerarse una unidad inseparable, esto se aplica también a propósito del ejercicio del derecho. Con base en la evidencia científica de que la lactancia es indispensable para la salud de ambos, tanto por fines nutritivos como para la construcción de vínculo afectivo y porque la leche humana es insustituible para el desarrollo integral de la niñez, en el sistema jurídico ecuatoriano se reconoce el derecho a la lactancia y se han planteado algunas medidas de protección.

La lactancia como derecho tiene ciertas particularidades que merecen ser mejor comprendidas, como la múltiple titularidad, la corresponsabilidad de protección y el ejercicio amplio en duración, continuidad y espacio. Como titulares principales del derecho a la lactancia están las mujeres y los niños y niñas, mientras se mira al Estado como responsable de garantizarlo. Al profundizar el análisis se identifican otros titulares vinculados del derecho, y otros actores sociales responsables de su garantía, como los miembros de la familia, empleadores y la sociedad en general. 
El goce del amamantamiento como derecho pierde eficacia cuando las entidades estatales y sociales, a través de normas, políticas y prácticas culturales, de manera directa o indirecta amenazan o vulneran el derecho a la lactancia y otros derechos vinculados, que inciden en la salud, física y psicológica, hasta atentan contra la vida de las madres y de sus hijos e hijas. Los derechos de las mujeres y de la niñez, aunque ya están reconocidos internacionalmente en varios instrumentos de derechos humanos, y en la legislación del Ecuador, para efectos del derecho a la lactancia, no se los visualiza como interdependientes e indivisibles, por lo que sus titulares están expuestos a discriminación, por visiones adultocéntricas y sexistas.

A pesar de que los principios de igualdad de género y la doctrina de protección integral están consagrados en la constitución ecuatoriana, el desarrollo normativo no ha combinado estos elementos a propósito de la lactancia y se genera una especie de confrontación entre el derecho de la madre a ser informada para tomar decisiones libres de toda influencia comercial, y el derecho de su hijo o hija. El empoderamiento y la autonomía de las mujeres cobra relevancia en la lactancia, son la clave para el ejercicio efectivo del derecho y para superar los obstáculos que provocan graves resultados en la vida de niños y niñas, en la madre, su familia y en la misma sociedad.

La lactancia es un derecho, pero a sus titulares principales no se les puede obligar a ejercerlo, ya que se requiere de apoyo y atención prioritaria para lograr practicarla sin limitaciones, según cada circunstancia. Los niños y niñas tienen el interés superior de recibir la mejor nutrición posible y todas las ventajas que implica la lactancia, por lo que es indispensable hacer una lectura adecuada sobre las relaciones humanas, los roles sociales y la percepción que se tiene sobre las responsabilidades paternas y maternas en la crianza de los hijos.

\section{Referencias}

Agra Viforcos, B. (2006). El embarazo y la lactancia: análisis desde la perspectiva de la prevención de riesgos en el trabajo. Boletín de la Facultad de Derecho de la UNED, N. ${ }^{\circ} 28$, pp. $151-182$.

Andres, L. (2015). Las mujeres y el derecho laboral ecuatoriano desde el enfoque de género. Una mirada a la Ley orgánica para la justicia laboral y el reconocimiento del trabajo del hogar. Revista de Estudios Jurídicos, 18 -31. 
Arias de la Torre, E.; Mejía Mejía, Y. (2015). Deterioro de la lactancia materna en la mujer trabajadora, una revisión de la literatura. México. Recuperado de: http:// www.convencionsalud2015.sld.cu/index.php/convencionsalud/2015/paper/ download/1337/1004

Ballester Pastor, M.A, (2019) El RDL 6/2019 para la garantía de la igualdad de trato y de oportunidades entre mujeres y hombres en el empleo y la ocupación: Dios y el diablo en la tierra del sol. Revista Andaluza de Trabajo y Bienestar Social, N. ${ }^{\circ} 146$, 13-40.

Bareiro, L. (2016). Situación de los derechos de las mujeres en América Latina y el Caribe, documento presentado en las tres reuniones subregionales preparatorias de la XIII Conferencia Regional sobre la Mujer de América Latina y el Caribe, Ciudad de México, Santiago de Chile y Puerto España, Comisión Económica para América Latina y el Caribe (CEPAL), inédito.

Bidegain Ponte, N. (2017). La Agenda 2030 y la Agenda Regional de Género: sinergias para la igualdad en América Latina y el Caribe. CEPAL Serie Asuntos de Género 143.

Butler J. (2006). Deshacer el género. Barcelona: Ediciones Paidós.

Cajas Córdova A. (2011). Igualdad de género en la constitución ecuatoriana de 2008. Aportes Andinos, Revista Electrónica de Derechos Humanos, N. ${ }^{\circ} 29$.

CEPAL (2011). Informe anual del 2011 del Observatorio de Igualdad de Género de América Latina y el Caribe. El salto de la autonomía. De los márgenes al centro (LC) W436). Santiago de Chile: Naciones Unidas.

Cillero, M. (1999). Infancia, autonomía y derechos: una cuestión de principios. Minoridad y Familia. Revista Interdisciplinaria sobre la Problemática de la NiñezAdolescencia y el grupo familiar N. ${ }^{\circ}$ 10. Recuperado en: http://www.iin.oea.org/ Cursos_a_distancia/explotacion_sexual/Lectura4.Infancia.DD.pdf

De Sousa Santos Boaventura, (2003). La caída del Angelus Novo. Ensayos para una nueva teoría social y una nueva práctica política. Bogotá: Editorial Universidad Nacional de Colombia.

Facio A., (1999). Feminismo, género y patriarcado. Recuperado de: http://justiciaygenero. org.mx/publicaciones/facio-alda-1999-feminismo-genero-y-patriarcado/

IBFAN (2006). Boletines año 4, 174-177 Octubre-Noviembre. Recuperado de: https:// laligadelaleche.eu/wp-content/uploads/Riesgos-de-la-alimentaci\%C3\%B3n-conleche-artificial-1.pdf

LIGA DE LA LECHE ARGENTINA y VOICES. (2018). Encuesta Nacional de lactancia y trabajo. Recuperado de: https://www.comunicarseweb.com/sites/default/files/ resultados.pdf

Massó Guijarro, E. (2013). Deseo lactante: sexualidad y política en el lactivismo contemporáneo. Revista de Antropología Experimental, N. ${ }^{\circ} 13$, 515-529.

. (2013). Lactancia materna y revolución, o la teta como insumisión biocultural: calostro, cuerpo y cuidado. Dilemata año $5,{ }^{\circ}{ }^{\circ} 11,169-206$. 
Marín Alonso, I. (2019). La tutela preventiva de la lactancia natural y discriminación por razón de sexo en la praxis judicial europea y nacional: la inversión de la carga de la prueba en supuestos de incorrecta evaluación de riesgos laborales. Cuadernos de Derecho Transnacional Vol. 11, No 1, pp. 459-477

OIT Organización Internacional del Trabajo (2010). La maternidad en el trabajo: Examen de la legislación nacional. Ginebra: Oficina Internacional del Trabajo.

(2003) La hora de la igualdad en el trabajo, Ginebra: Oficina Internacional del Trabajo, Recuperado de: http://www.oit.org/ilolex/spanish/ .

(2014). La maternidad y la paternidad en el trabajo. La legislación y la práctica en el mundo. Ginebra: Oficina Internacional del Trabajo. Recuperado de: https://www. ilo.org/wcmsp5/groups/public/---dgreports/---dcomm/documents/publication/ wcms_242618.pdf

OMS Organización Mundial de la Salud (2017) Lactancia materna, en Salud de la madre, el recién nacido, del niño y del adolescente. Recuperado de: http://www.who.int/ maternal_child_adolescent/topics/newborn/nutrition/breastfeeding/es/

(2013) Efectos a corto plazo de la lactancia. Una revisión sistémica de los beneficios de la lactancia materna en la mortandad por diarrea y neumonía (Short-term effects of breastfeeding. A systematic review on the benefits of breastfeeding on diarrhoea and pneumonia mortality). Ginebra: OMS. Recuperado de: https://apps. who.int/iris/bitstream/handle/10665/95585/9789241506120_eng.pdf;jsessionid = 2EE6D108456FF58B4D8E602730474454? sequence $=1$

(2012) Estrategia Mundial para la alimentación del Lactante y del Niño Pequeño. Ginebra: Mínimum Graphics; Ginebra: OMS. Recuperado de: http://www.unicef. org/ecuador/estrategia_mundial_para_la_alimentacion_del_lactante.pdf.

(2009) Razones médicas aceptables para el uso de sucedáneos de leche materna. Singapur: OMS. Recuperado de: https://www.who.int/nutrition/publications/ infantfeeding/WHO_NMH_NHD_09.01_spa.pdf

Datos sobre la alimentación del lactante y del niño pequeño. Recuperado de: https://www.who.int/nutrition/publications/infantfeeding/bfhi_trainingcourse_s2_ transparencies_es.pdf?ua $=1$

ONU Mujeres y Pacto Mundial de las Naciones Unidas (2011). Principios para el Empoderamiento de las Mujeres, Recuperado de: http://www2.unwomen. org/-/media/headquarters/attachments/sections/partnerships/businesses\%20 and\%20foundations/women-s-empowerment-principles_2011_es\%20pdf. pdf?v=1\&d=20141013T121818

(2016) Joint statement by the UN Special Rapporteurs on the Right to Food, Right to Health, the Working Group on Discrimination against Women in law and in practice, and the Committee on the Rights of the Child in support of increased efforts to promote, support and protect breast-feeding, Recuperado de: - http://www.ohchr. org/EN/NewsEvents/Pages/DisplayNews.aspx?NewsID=20871\&LangID=E A/ HRC/32/44, paras. 67 and 72 
ONU (1993) Declaración y Programa de Acción de Viena, Aprobados por la Conferencia Mundial de Derechos Humanos, ONU, 25 de junio de 1993. Recuperado de: https:// www.ohchr.org/Documents/Events/OHCHR20/VDPA_booklet_Spanish.pdf

OPS, UNIFEM, UNFPA (2007)Género, salud y desarrollo en las Américas. Indicadores básicos. Washington: OPS, 2007.

Ossorio, M.(2017). Diccionario de ciencias jurídicas, políticas y sociales. Recuperado de: https://argentina.leyderecho.org/lactancia/

Salgado J. (2010). Derechos de personas y grupos de atención prioritaria en la Constitución Política del Ecuador. En: Santiago Andrade, Agustín Grijalva, Claudia Storini, edit., La nueva Constitución del Ecuador: Estado, Derechos e Instituciones. Quito: Ministerio de Justicia.

UNICEF. (2018) Capturar el momento - Inicio temprano de la lactancia materna: El mejor comienzo para cada recién nacido, Nueva York UNICEF. Disponible en: https://www.unicef.org/spanish/publications/files/UNICEF_WHO_Capture_the_ moment_EIBF_2018_Sp.pdf

(2015) Iniciativa de defensa de la lactancia materna (Breastfeeding Advocacy Initiative), Nueva York: UNICEF y OMS. Disponible en: https://www.unicef.org/ nutrition/files/Breastfeeding_Advocacy_Strategy-2015.pdf

Universidad Autónoma de México, 2002. Lactancia Materna. México D. F.: UNAM

WABA (2016) Lactancia: una clave a Desarrollo Sustentable (Breastfeeding: A key to Sustainable Development) Recuperado de: http://worldbreastfeedingweek. org/2016/

Williams J. (2009). Igualdad sin discriminación. En: Ramiro Ávila, Judith Salgado y Lola Vallares, comp., El género en el derecho. Ensayos críticos: Quito: Ministerio de Justicia y Derechos Humanos.

\section{NORMAS JURÍDICAS}

Comisión Interamericana de Derechos Humanos. (2015) Estándares jurídicos: igualdad de género derechos de las mujeres. OEA/Ser.L/V/II.143 Doc. 60, 3 noviembre 2011 Actualización del 2011-2014.

(2007) Acceso a la justicia para las mujeres víctimas de violencia en las américas. OEA/Ser.L/V/II. Doc. 68, Washington D.C., 20 enero 2007

Corte Interamericana de Derechos Humanos (2002). Condición jurídica y derechos humanos del niño. Opinión Consultiva OC-17/2002.

Organización de Estados Americanos-OEA (1969) Convención Americana de Derechos Humanos (Pacto de San José), Adoptado en San José-Costa Rica, Entrada en Vigor: 18 de julio de 1978.

Organización de las Naciones Unidas - ONU (Asamblea General) (1948) Declaración Universal de Derechos Humanos (DUDH). Resolución 217 A (III). 
(1966) Pacto Internacional de Derechos Económicos Sociales y Culturales. Resolución 2200 A (XXI)1969.

(1979) Convención contra todas las formas de discriminación contra la mujer CEDAW, entrada en vigor el 3 de septiembre de 1981.

(1989) Convención de los Derechos del Niño (CDN). Resolución 44/25.

(Conferencia General de la Organización Internacional del Trabajo) (2000) Convenio OIT N. ${ }^{\circ} 183$. Convenio sobre la Protección de la maternidad. Ginebra, $88^{a}$ reunión CIT (15 junio 2000)

(Conferencia General de la Organización Internacional del Trabajo) (2000) Recomendación N. ${ }^{\circ} 191$ sobre protección de maternidad. Ginebra, $88^{a}$ reunión CIT (15 junio 2000).

(Comité para la eliminación de la discriminación contra la mujer) (2004) Recomendación General 25. Párrafo 1 del artículo 4 de la Convención sobre la eliminación de todas las formas de discriminación contra la mujer - Medidas especiales de carácter temporal. $30^{\circ}$ período de sesiones.

(Comité de los derechos del Niño) (2013) Recomendación General 14. sobre el derecho del niño a que su interés superior sea una consideración primordial (artículo 3 , párrafo 1) Aprobada por el Comité en su $62^{\circ}$ período de sesiones (14 de enero a 1 de febrero de 2013).

República del Ecuador (2008) Constitución de la República del Ecuador. Decreto Legislativo N. ${ }^{\circ}$ 0, Registro Oficial 449, de 20 de octubre de 2008.

(1995) Ley de Fomento, Apoyo y Protección a la Lactancia Materna. Ley N. 101, Registro Oficia. N. 814. de 1 de noviembre de 1995.

(2003) Código Orgánico de la Niñez y Adolescencia, Ley N. ${ }^{\circ}$ 100, Registro Oficial N. ${ }^{\circ} 737$, de 3 de enero de 2003.

(2005) Código de Trabajo, Codificación, Registro Oficial Suplemento N. 167, de 16 de diciembre de 2005.

(2010) Ley Orgánica del Servicio Público, Registro Oficial Suplemento N. ${ }^{\circ} 294$, de 6 de octubre de 2010.

(2015) Ley Orgánica Justicia Laboral y Reconocimiento del Trabajo en Hogar, Registro Oficial Suplemento N. ${ }^{\circ}$ 483, de 20 de abril de 2015.

(2016) Ley Orgánica de Gestión de la Identidad y Datos Civiles (LOGIDAC), Registro Oficial Suplemento N. ${ }^{\circ}$ 684, de 4 de febrero de 2016.

(2018) Ley para Prevenir y Erradicar la Violencia contra las Mujeres, Registro Oficial Suplemento N. ${ }^{\circ} 175$, de 5 de febrero de 2018.

(2019) Norma para uso de salas de apoyo a lactancia materna, sector privado, Acuerdo Ministerial N. ${ }^{\circ}$ 3, Registro Oficial N. ${ }^{\circ} 473$ de 23 de abril de 2019. 


\section{WEBGRAFÍA:}

BBC (2019). Cuál es el precio de un litro de leche materna y por qué Noruega lo cuenta en su PIB. 16 de junio de 2019. Recuperado de: https://www.bbc.com/mundo/ noticias -48638778

El Espectador (2019) Lactancia, un "negocio" que les quieren robar a las madres; 30 de mayo de 2019. Recuperado de https://www.elespectador.com/noticias/salud/ lactancia-un-negocio-que-le-quieren-robar-las-madres-articulo-863567

El Mundo. Aumentar la lactancia podría evitar 800000 muertes infantiles http://www. elmundo.es/salud/2016/01/29/56aab46d46163f71368b45e6.html. Recuperado el 31 de agosto de 2018.

(2009) Entrevista al pediatra Carlos González, experto en lactancia 'La edad normal del destete debe estar entre los dos años y medio y los siete' Recuperado de: https://www.elmundo.es/elmundosalud/2009/08/01/mujer/1249085191.html 